\title{
Progesterone promotes focal adhesion formation and migration in breast cancer cells through induction of protease-activated receptor-1
}

\author{
Jorge Diaz ${ }^{1,5}$, Evelyn Aranda ${ }^{1}$, Soledad Henriquez ${ }^{1}$, Marisol Quezada ${ }^{1}$, Estefanía Espinoza ${ }^{1}$, \\ Maria Loreto Bravo ${ }^{1}$ Bárbara Oliva ${ }^{1}$, Soledad Lange ${ }^{2}$, Manuel Villalon ${ }^{1}$, Marius Jones ${ }^{3}$, Jan J Brosens ${ }^{3}$, \\ Sumie Kato ${ }^{1,2}$, Mauricio A Cuello ${ }^{2}$, Todd P Knutson ${ }^{4}$, Carol A Lange ${ }^{4}$, Lisette Leyton ${ }^{5}$ \\ and Gareth I Owen ${ }^{1,6}$ \\ ${ }^{1}$ Departamento de Fisiología, Facultad de Ciencias Biológicas and ${ }^{2}$ Departamento de Ginecología, Facultad de Medicina, Pontificia Universidad Católica de \\ Chile, Alameda 340, Santiago, Chile \\ ${ }^{3}$ Clinical Sciences Research Laboratories, Division of Reproductive Health, Warwick Medical School, University Hospital, Coventry CV2 2DX, UK \\ ${ }^{4}$ Departments of Medicine and Pharmacology, Masonic Cancer Center, University of Minnesota, Minneapolis, Minnesota, USA \\ ${ }^{5}$ Centro de Estudios Moleculares de la Célula (CEMC), Facultad de Medicina, Universidad de Chile, 838-0453 Santiago, Chile \\ ${ }^{6}$ Biomedical Research Consortium (BMRC) Chile, Alameda 440, Santiago, Chile \\ (Correspondence should be addressed to G I Owen at Departamento de Fisiología, Facultad de Ciencias Biológicas, Pontificia Universidad Católica de Chile; \\ Email: gowen@bio.puc.cl)
}

\begin{abstract}
Progesterone and progestins have been demonstrated to enhance breast cancer cell migration, although the mechanisms are still not fully understood. The protease-activated receptors (PARs) are a family of membrane receptors that are activated by serine proteases in the blood coagulation cascade. PAR1 (F2R) has been reported to be involved in cancer cell migration and overexpressed in breast cancer. We herein demonstrate that PAR1 mRNA and protein are upregulated by progesterone treatment of the breast cancer cell lines ZR-75 and T47D. This regulation is dependent on the progesterone receptor (PR) but does not require PR phosphorylation at serine 294 or the PR proline-rich region mPRO. The increase in PAR1 mRNA was transient, being present at $3 \mathrm{~h}$ and returning to basal levels at $18 \mathrm{~h}$. The addition of
\end{abstract}

a PAR1-activating peptide (aPAR1) to cells treated with progesterone resulted in an increase in focal adhesion (FA) formation as measured by the cellular levels of phosphorylated FA kinase. The combined but not individual treatment of progesterone and aPAR 1 also markedly increased stress fiber formation and the migratory capacity of breast cancer cells. In agreement with in vitro findings, data mining from the Oncomine platform revealed that PAR1 expression was significantly upregulated in PR-positive breast tumors. Our observation that PAR 1 expression and signal transduction are modulated by progesterone provides new insight into how the progestin component in hormone therapies increases the risk of breast cancer in postmenopausal women.

Journal of Endocrinology (2012) 214, 165-175

\section{Introduction}

Progesterone is an essential hormone in the process of breast development and differentiation (Horwitz et al. 1990). Given the requirement of breast cells to proliferate, migrate, and invade during the luteal phase and pregnancy, it has been speculated that progestins hijack these signaling pathways in breast cancer cells. Progesterone and progestins have been previously reported to stimulate breast cancer cell migration and invasion (Carvajal et al. 2005, Kato et al. 2005b, Fu et al. 2008). Indeed, in postmenopausal women receiving hormone replacement therapy (HRT), the presence of progestagenic compounds increases breast cancer incidence (Beral 2003). To deliver their proliferative and invasive responses, progestagenic compounds use the progesterone receptor (PR).
Post-translational modifications such as sumoylation and phosphorylation have been shown to alter PR transcriptional activity. Phosphorylation of PR Ser-294 augments PR degradation by the $26 \mathrm{~S}$ proteasome and also blocks PR Lys-388 sumoylation, a reversible ligand-induced modification that blunts $\mathrm{PR}$ transcriptional response on certain progesterone-regulated genes (Lange et al. 2000, Daniel \& Lange 2009). PRs engineered to be defective in either Ser-294 (S294A) or in the ability to bind to and activate c-Src-dependent intracellular signaling to MAPKs (PR-mPro) have shown the requirement for PR-induced rapid activation of $\mathrm{c}-\mathrm{Src}$ and MAPKs in proliferative responses stimulated by progestagenic compounds (Faivre et al. 2005).

For anchorage-dependent migration to occur, a coordinated interplay of filopodia and lamellipodia protrusions at the 
leading cellular edge, the formation of focal contacts with the extracellular matrix and their maturation into focal adhesions (FAs), contraction of the cell body, and finally detachment at the rear of the cell is required (Abreu et al. 2011). One of the most studied components of the FA complexes in adherent cells is FA kinase (FAK), which was initially described as a downstream target of the viral oncogene $\mathrm{v}$-Src, but has now been described as one of the major mediators of integrin signaling (Schaller et al. 1992, Zhao \& Guan 2009). FAK belongs to a subfamily of cytoplasmic tyrosine kinases, which lack Src homology domains $\mathrm{SH} 2$ and $\mathrm{SH} 3$. In a nonactive state, the N-terminal FERM domain of the FAK protein prevents access to its catalytic loop and prevents autophosphorylation of the kinase domain. Upon activation, FAK associates with FA proteins allowing autophosphorylation at residue tyrosine 397, which serves as a docking site for $\mathrm{SH} 2$ domain containing $\mathrm{Src}$ and PI3K (through the p85 subunit). This interaction and initial phosphorylation event displaces the FERM domain and is followed by further phosphorylation at tyrosine $567 / 577$ (Fu et al. 2008, Schaller 2008, Guan 2010). Mature FA complexes, together with phosphorylated FAK, require the further recruitment of proteins, such as vinculin, talin, and paxillin, among others (Burridge \& Chrzanowska-Wodnicka 1996, Critchley 2000). A role of FAK in cell migration is now widely accepted through key experiments demonstrating that FAK overexpression promotes wound repair in in vitro assays, FAK knockout fibroblasts show decreased migration capabilities, and FAK inhibition prevents endothelial cell movement (Zhao \& Guan 2009).

A recent study on the progesterone-responsive T47D breast cancer cell line demonstrated that progesterone could enhance FAK phosphorylation and increase the number of FA complexes within specialized cellular membrane protrusions (Fu et al. 2008). This phosphorylation at both tyrosine 397 and 567/577 was rapid and transient, occurring within $15 \mathrm{~min}$ and returning to basal levels at $1 \mathrm{~h}$. Maximum stimulation occurred at the physiological concentration of $10 \mathrm{nM}$, a progesterone concentration previously reported to be optimal in both the PR-positive ZR-75 and T47D cell lines (Kato et al. 2005b). In the T47D cell line, a progesteronedependent increase in FAK phosphorylation was shown to be dependent on both Src signaling and the PR, although whether this involved direct interaction between both signaling molecules through the Src interaction domain of PR was investigated (Boonyaratanakornkit et al. 2001, Pierson-Mullany \& Lange 2004, Faivre \& Lange 2007, Faivre et al. 2008, Fu et al. 2008). The same study further provided evidence that RHOA and ROCK2 signaling proteins are also essential. The ROCK protein kinase family has also been given a pivotal role within the signaling network controlling actomyosin contractility and stress fiber assembly (Leung et al. 1996, Pellegrin \& Mellor 2007). Interestingly, migration of T47D breast cancer cells is blocked not only by PR and PI3K pathway inhibitors but also by inhibitors of $G$ proteins and the MAPK pathway (MEK1/2), demonstrating that multiple signals are required to permit or maintain
FAK-mediated cell migration in response to progesterone signaling (Fu et al. 2008).

The protease-activated receptors (PARs) are a family of four vascular receptors that respond to local changes in the proteolytic environment. PAR1 (F2R) to PAR4 (F2RL3) are $\mathrm{G}$ protein-coupled receptors activated by serine proteases of the blood coagulation cascade pathways, notably thrombin (Hirano 2007, Landis 2007). Many of the PAR-activating proteases are produced during tissue damage, and thus PARs make important contributions to tissue responses to injury, which include hemostasis, cell survival responses, inflammation, pain, and repair (Ossovskaya \& Bunnett 2004). However, only PAR1, PAR3 (F2RL3), and PAR4 are referred to as thrombin receptors due to thrombin's ability to specifically cleave the extracellular N-termini of the receptor (Yuan \& Lin 2004). Signaling through PARs has been demonstrated to influence a wide range of physiological responses including inflammation, platelet activation, vascular tone maintenance, and barrier function (Leger et al. 2006). In tumor cells, the factor VIIa-tissue factor (TF) complex activates PAR2 and thereby regulates proangiogenic growth factor expression (Ruf \& Mueller 2006). Interestingly, TF is strongly induced by progesterone in both the T47D and ZR-75 breast cancer cell lines (Kato et al. 2005b), which in turn increase the procoagulant activity of breast cancer cells (Kato et al. 2005b, Henriquez et al. 2011).

The ability of progesterone and progestins to regulate PAR expression appears to be cell specific. For example, levonorgestrel, a widely used progestin, was shown to downregulate PAR1 expression in human endometrium (Hague et al. 2002). However, in vascular smooth muscle cells and the rat aorta, medroxyprogesterone acetate and several other progestins upregulate PAR1 expression, yet levonorgestrel and the synthetic estrogen $17 \alpha$-ethinylestradiol do not confer the same effect (Herkert et al. 2001). In the ovine cervix, PAR 1 and PAR2 are expressed in the luminal epithelium of the cervix throughout the estrus cycle, with expression peaking at estrus. The synchronization of estrus by a progesterone sponge increased PAR2 but not PAR1 expression (Mitchell et al. 2005). Furthermore, it has been suggested that PAR1 plays a key role in signaling events preceding menstrual bleeding (Critchley et al. 2006). However, currently no reports exist of progesterone regulation of PARs in normal or malignant breast cells.

Overexpressed PAR1 is a feature of many metastatic cancers (Even-Ram et al. 1998, Tellez \& Bar-Eli 2003, Yin et al. 2003). Cancer cells overexpressing PAR1 are more invasive in vitro, and this is further enhanced by a PAR1activating ligand (Even-Ram et al. 2001). We have previously reported on a correlation between metastasis and the expression of TF, which is known to cleave and activate PAR1 and PAR2 (Kato et al. 2005a,b). Other clotting intermediates have also been associated with the cancer progression, angiogenesis, and metastasis, such as thrombin, factor $\mathrm{Xa}$ and plasminogen activator inhibitor, type 1 (Rickles 2006). These observations suggest that signaling 
events downstream of these clotting cascade factors deliver a survival advantage to cancer cells. In this study, we examined the possibility that progesterone impacts on the behavior of breast cancer cells by engaging PAR-dependent signaling (Rickles 2006).

\section{Materials and Methods}

\section{Cell culture and hormonal treatment}

The breast cancer cell lines ZR-75 (Engel et al. 1978), T47Dco (T47D), T47D-YB (Sartorius et al. 1994), T47D PR S294A, and T47D PR mPRO (Pierson-Mullany \& Lange 2004, Faivre \& Lange 2007, Faivre et al. 2008) were maintained in DMEM/F12 media supplemented with 10\% fetal bovine serum (FBS; Invitrogen). To obtain protein and RNA, cells were plated at $50 \%$ confluence in $10 \mathrm{~cm}^{2}$ Petri dishes (Falcon, Becton-Dickinson, Franklin Lakes, NJ, USA). For immunocytochemistry, coverslips were added to the dishes. Culture medium was changed to charcoal-treated medium containing $5 \%$ serum for $24 \mathrm{~h}$ before hormone or epidermal growth factor (EGF) treatment. The steroid hormones progesterone or estrogen (17 $\beta$-estradiol $\left(E_{2}\right)$, (both Sigma-Aldrich)) were dissolved in ethanol and added to the cells, at a final concentration of $10 \mathrm{nM}$. R5020 was purchased from NEN and used at $20 \mathrm{nM}$. EGF (Upstate Biotechnology, NY, USA) was added at a final concentration of $10 \mathrm{nM}$ in water. An equal volume of ethanol was added as a control in the EGF treatments. For immunocytochemistry and migration experiments, a PAR1-activating peptide (aPAR1), H-Thr-Phe-Leu-LeuArg- $\mathrm{NH}_{2}$ (TFLLRN purchased from Gen Script Corporation, NJ, USA), was added as stated in the figure legends.

\section{Western blotting}

Protein was isolated as previously published (Kato et al. 2005b), and $100 \mu \mathrm{g}$ protein extract was loaded in each lane. Breast cancer cells fixed onto coverslides were incubated for $18 \mathrm{~h}$ with PAR1 primary antibody (Santa Cruz Biotechnology, Santa Cruz, CA, USA) at a final dilution of 1:100. The secondary antibody was a goat anti-mouse/ rabbit IgG secondary antibody coupled with HRP (1:5000, Bio-Rad Laboratories), used for $1 \mathrm{~h}$ at room temperature. Bound antibody was detected by chemiluminescence using the ECL western blot analysis system (NEN, Western lightning; Perkin-Elmer (Waltham, MA, USA)).

\section{RT-PCR}

Total RNA isolation and cDNA generation were as previously published (Kato et al. 2005b). Using PAR1 primers, sense: $5^{\prime}$-TGT ACG CCT CTA TCT TGC TCA TGA C-3', antisense: $5^{\prime}$-GCA GGT ATG CAA GTC GTA CAT CTG-3' (BiosChile, Santiago, Chile) semiquantitative PCRs were performed from cDNA generated from progesterone, estrogen EGF, and RU486-treated samples, using Taq polymerase (Invitrogen). Cycle curves were performed for all sets of PCR primers, with the number of cycles used for each primer set being in the linear range of the curve. Primers amplifying a region of glyceraldehyde-3phosphate dehydrogenase (GAPDH) were used to act as an internal loading control: sense: $5^{\prime}-\mathrm{ccc}$ ctg gcc aag gtc atc cat gac- $3^{\prime}$, antisense: $5^{\prime}-c c c$ ctc ccc tct tca agg ggt cta $c-3^{\prime}$; BiosChile). NET1 primers have been previously reported (Bray et al. 2005) The MEK1/2 (U0126, $10 \mu \mathrm{M}$; Calbiochem, La Jolla, CA, USA), Src (PP2, $10 \mu \mathrm{M}$; Calbiochem), and EGFR (AG1478, $1 \mu \mathrm{M}$; Calbiochem) pathway inhibitors were added $30 \mathrm{~min}$ before progesterone or vehicle addition. Semiquantitative densitometry of the bands was performed using $\mathrm{NIH}$ Image 1.62c Software package for Macintosh (NIH, Bethesda, MD, USA). Mann-Whitney analysis was used to determine significant variations, with a level of significance set at $P<0 \cdot 05$.

\section{Migration assays}

ZR-75 cells were seeded onto porous inserts ( $8 \mu \mathrm{m}$, Nunc) previously coated with matrigel (Sigma-Aldrich). Progesterone $(10 \mathrm{nM})$ or vehicle was added for $24 \mathrm{~h}$. An activating PAR 1 peptide was added $12 \mathrm{~h}$ before the end of the experiment. The Nunc inserts were fixed in cold methanol and immunocytochemistry against cytokeratin (Sigma-Aldrich) was performed. Observation under light microscopy determined the number of cells in each field that had passed through the porous membrane. In each dataset, 15 fields $(400 \times)$ were counted and the mean number of cells was plotted with standard errors. Four separate experiments were performed for each reported point. Mann-Whitney analysis was used to determine significant variations, with a level of significance set at $P<0 \cdot 05$.

\section{Immunocytochemistry}

PAR1 antibody (Calbiochem) was added for $18 \mathrm{~h}$ at a dilution of 1:100. The coverslides received two $30 \mathrm{~min}$ washes before labeled Streptavidin Biotin, LSAB ${ }^{\mathrm{TM}}$ (DAKO, CA, USA) addition for a further for $30 \mathrm{~min}$. The image was developed using diaminobenzidine for $15 \mathrm{~min}$ in darkness and counterstained with Harris hematoxylin before mounting.

\section{Immunofluorescence}

ZR-75 cells $\left(2 \times 10^{4}\right.$ cells $)$ were seeded on $12 \mathrm{~mm}$ coverslips inserted in 24-well plates and incubated for $24 \mathrm{~h}$ in DMEM/F12 containing 5\% FBS. Progesterone $(10 \mathrm{mM})$ was then added to the cells and incubated for an additional $24 \mathrm{~h}$. The medium was then replaced by serum-free medium and after $30 \mathrm{~min}$ incubation, aPAR1 (A1, $100 \mu \mathrm{M})$ was added for $15 \mathrm{~min}$. Next, cells were fixed with $4 \% p$-formaldehyde in $100 \mathrm{mM}$ PIPES buffer, $\mathrm{pH} 6 \cdot 8$, containing $0.04 \mathrm{M} \mathrm{KOH}$, $2 \mathrm{mM}$ EGTA, and $2 \mathrm{mM} \mathrm{MgCl}$, permeabilized with $0 \cdot 1 \%$ Triton X-100 in Universal buffer $(50 \mathrm{mM}$ Tris-HCl, 
$\mathrm{pH} 7 \cdot 6,0 \cdot 15 \mathrm{M} \mathrm{NaCl}$, and $0 \cdot 1 \%$ sodium azide) for $10 \mathrm{~min}$, and blocked with 2\% BSA in Universal buffer for $30 \mathrm{~min}$. Cells were then incubated with anti-phospho-FAK $\mathrm{IgG}$, followed by FITC-conjugated anti-rabbit IgG, rhodamine-labeled phalloidin, and 4',6-diamidino-2-phenylindole (DAPI) for $1 \mathrm{~h}$. Samples were then mounted onto slides with 10\% Mowiol (Calbiochem) and 2.5\% 1,4-diazabicyclo[2,2,2]octane (DABCO, Sigma) and visualized using an IX-81 spinning disc microscope (Olympus, Center Valley, PA, USA). Visualization of polymerized actin by rhodamine-labeled phalloidin allowed the quantification of the number of individual cells that contained stress fibers under each experimental condition. The number of FAs was counted as previously reported (Avalos et al. 2004).

\section{Data mining using the Oncomine platform}

Oncomine (Compendia Bioscience, Ann Arbor, MI, USA) was used for analysis and visualization. Oncomine is an online tool that aggregates mRNA and copy number expression data from various studies related to cancer. Oncomine contains data from over 18000 cancer gene expression microarrays and allows a researcher to easily investigate the relative expression of a particular gene across various cancer datasets (including human tumors and cell lines; Rhodes et al. 2004, 2007). Herein, we employed the recently updated TCGA breast cancer dataset, where each tumor sample was genome sequenced and analyzed for mRNA expression, DNA copy number, DNA methylation, etc. The Oncomine database collected and standardized this information for our analysis. PAR1 mRNA expression was investigated in breast tumors and sorted based on PR status (as provided in the metadata for each tumor sample, i.e. PR clinical immunohistochemistry (IHC) report, either positive or negative).

\section{Results}

Progesterone regulates $P A R 1 m R N A$ and protein in the $Z R-75$ breast cancer cell line

To investigate the regulation of $P A R 1$, we determined the $P A R 1$ transcript levels in $\mathrm{ZR}-75$ breast cancer cells stimulated for $9 \mathrm{~h}$ with progesterone $(10 \mathrm{nM}), \mathrm{E}_{2}(10 \mathrm{nM})$, or EGF $(10 \mathrm{nM})$. Figure 1A demonstrates that only progesterone increases PAR $1 \mathrm{mRNA}$ levels in these cells. Adding estrogens did not alter the ability of progesterone to increase PAR1 transcript levels, and this effect was also replicated using the synthetic progestin medroxyprogesterone acetate (results not shown). To further dissect the progesterone regulation of $P A R 1$, we performed a $24 \mathrm{~h}$ time course to examine mRNA. As seen in Fig. 1B, the progesterone upregulation is rapid and transient, being elevated at $3 \mathrm{~h}$, reaching a maximum at $6 \mathrm{~h}$, and plateauing out at $12 \mathrm{~h}$, before the levels return to basal values at 18 and $24 \mathrm{~h}$ (Fig. 1B). The dependence on transcription and the $\mathrm{PR}$ was demonstrated by the inability of progesterone to increase PAR $1 \mathrm{mRNA}$ after $9 \mathrm{~h}$ in the presence of the competitive PR antagonist, RU486 (100 nM, Fig. 1C), and the transcription inhibitor actinomycin-D $(10 \mu \mathrm{g} / \mathrm{ml}$, Fig. 1D). To demonstrate that this increase in
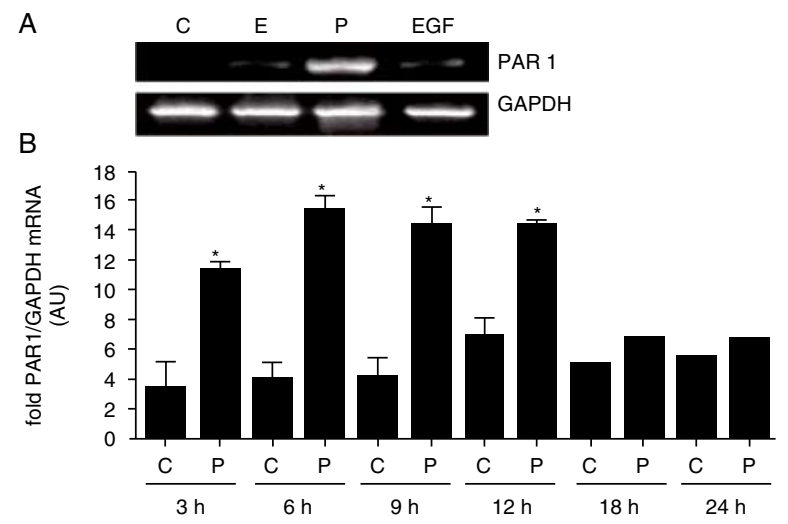

C

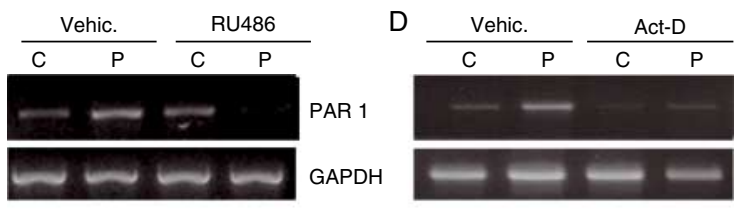

E
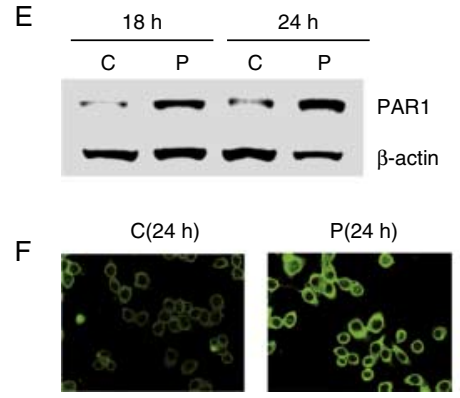

Figure 1 Progesterone upregulates PAR1 mRNA and protein in the ZR-75 cell line. (A) The effects of ovarian hormones and EGF upon PAR1 mRNA expression levels. ZR-75 cells were incubated for $9 \mathrm{~h}$ in DMEM/F12 with 5\% charcoal-treated serum containing vehicle (C, ethanol), $10 \mathrm{nM}$ progesterone (P), $10 \mathrm{nM} 17 \beta$-estradiol (E), or $10 \mathrm{nM}$ EGF treatments. RT-PCR products were separated on a $1 \cdot 5 \%$ agarose gel and stained with ethidium bromide. Equal starting RNA concentrations were confirmed by GAPDH amplification.

(B) Time course of PAR1 mRNA levels in response to progesterone in ZR-75 cells. Cells were treated with a single pulse of progesterone $(10 \mathrm{nM})$ and harvested at indicated times between 0 and $24 \mathrm{~h}$. Densitometric analysis was obtained from a minimum of three independent experiments. Mann-Whitney analysis was used to determine statistical significance, $* P<0 \cdot 05$. (C and D) RT-PCR in which progesterone $(10 \mathrm{nM})$ treatment was for $9 \mathrm{~h}$ and RU486 $(100 \mathrm{nM})$ or actinomycin-D (Act-D, $10 \mu \mathrm{g} / \mathrm{ml})$ addition 30 min before progesterone addition. GAPDH was used as an internal control. (E) Cells were treated as earlier with $10 \mathrm{nM}$ progesterone for 18 or $24 \mathrm{~h}$ before protein extraction and PAR1 analysis by western blot. Equal protein loading was verified by an anti- $\beta$-actin antibody. (F) ZR-75 cells were grown on coverslides for $24 \mathrm{~h}$ in the presence of vehicle or progesterone under the conditions stated earlier. PAR1 immunoreactivity was more pronounced in the presence of progesterone. Full colour version of this figure available via http://dx.doi.org/10.1530/JOE-11-0310. 
mRNA expression translated into increased protein levels, we examined PAR1 levels by western blotting and immunocytochemistry in ZR-75 cells treated with progesterone for 18 or $24 \mathrm{~h}$. As shown in Fig. $1 \mathrm{E}$ and F, progesterone strongly enhanced the cellular expression of this PAR family member at both time points.

Progesterone regulates PAR $1 m R N A$ and protein in the T47D breast cancer cell line

To demonstrate that the progesterone-dependent regulation of PAR 1 was not restricted to ZR-75 cells, we turned to T47D cells, another well-characterized progesterone-responsive breast cancer cell line (Horwitz et al. 1982). As shown in Fig. 2A, progesterone also increased PAR1 mRNA levels in this cell line and the kinetics of this response appeared similar to that observed in ZR-75 cells. To determine whether PR-dependent transcription mediates the effect of progesterone on PAR 1 expression, we made use of a PR-negative T47D clone stably transfected with PR-B
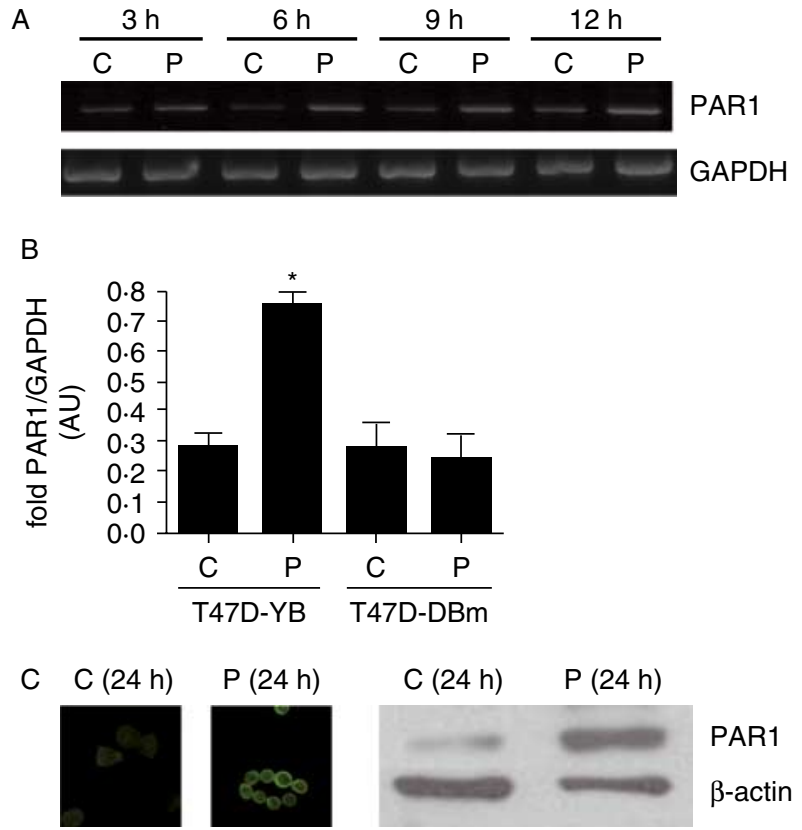

Figure 2 Progesterone upregulates PAR1 mRNA and protein in the T47D cell line. (A) Representative time course of PAR1 mRNA levels in response to progesterone in T47D cells. Cells were treated with a single pulse of progesterone $(10 \mathrm{nM})$ and harvested at indicated times between 0 and $12 \mathrm{~h}$. (B) PAR1 mRNA levels in response to progesterone in the T47D-YB and T47D-DBDm cell lines. Densitometric analysis from a minimum of three independent experiments is shown. Mann-Whitney analysis was used to determine statistical significance, $* P<0 \cdot 05$. In both panels $A$ and $B$, GAPDH was used as an internal loading control. (C) T47D cells were treated with $10 \mathrm{nM}$ progesterone $(\mathrm{P})$ or vehicle $(C)$ for $24 \mathrm{~h}$ before analysis of PAR1 by immunoreactivity (left-hand panel) or by western blotting (right-hand panel). Equal protein loading was verified by an anti- $\beta$-actin antibody. Full colour version of this figure available via http://dx.doi.org/10.1530/JOE-11-0310.
(T47D-YB) and a clone containing a PR mutant unable to bind DNA (T47D-DBm) (Sartorius et al. 1994). As shown in Fig. 2B, the progesterone-dependent regulation of PAR1 expression was dependent on the presence of transcriptionally competent PR-B. Again, the increase in PAR1 mRNA upon progesterone stimulation increases correspondingly protein levels in T47D cells (Fig. 2C).

Progesterone-dependent regulation of PAR 1 expression does not require $E G F R, M E K 1$, or $c$-Src signaling

As progesterone actions are modified through targeted phosphorylation of PR by the MAPK, c-Src, and the EGFR signal transduction pathways (Lange 2008), we investigated whether inhibitors of these pathways also impinge on the induction of PAR 1 transcripts. As shown in Fig. $3 \mathrm{~A}$ and $\mathrm{B}$, none of the pharmacological inhibitors, at concentrations previously validated in ZR-75 cells, attenuated the progesterone induction of PAR 1 transcripts. To confirm this result, we again made use of T47D cells stably expressing specific PR mutants that either lack the MAPK phosphorylation site (S294A) or the proline-rich Src interaction motif (mPRO) (Quezada et al. 2010, Pierson-Mullany \& Lange 2004, Faivre \& Lange 2007, Faivre et al. 2008). As anticipated from the inhibitor studies, these $\mathrm{PR}$ mutants were as effective as wild-type PR-B in inducing PAR 1 expression upon progesterone activation (Fig. 3C and D). As the mutant S294A PR-B had previously been reported to possess limited transcriptional activity (on selected endogenous genes), we tested whether our cell lines maintained this response on additional progesteroneregulated genes. As demonstrated in Fig. 3E, progestin is capable of regulating NET1 mRNA levels via wild-type PR but not in cells stably expressing S294A PR. These data confirm that S294A mutant receptors function as previously reported and that this phosphorylation site positively impacts PR transcription in a promoter selective manner. By contrast, herein, our data clearly demonstrate that PR Ser294 is not required for progesterone-dependent regulation of PAR 1 .

Progesterone promotes focal contacts, stress fiber formation, and cell migration upon PAR 1 activation

To evaluate whether progesterone-dependent increase in PAR-1 expression is of biological relevance, we focused on cell migration. Cell migration requires formation of focal contacts, mediated by phosphorylated FAK, and the creation of stress fibers. The presence of focal contacts was confirmed by co-localization of phosphorylated FAK with vinculin (not shown). Although PAR1 is expressed in ZR-75 cells in the absence of progesterone stimulation, treatment with a specific aPAR1 did not increase the number of focal contacts per cell. Similarly, progesterone treatment alone had no discernible effect. However, pretreatment with progesterone, which upregulates PAR1 expression, followed by the addition of the activating peptide resulted in a significant increase in focal 
contacts (Fig. 4A and B). The same pattern of regulation was observed upon the examination of stress fibers using phalloidin staining (Fig. 5A and B). Although progesterone treatment alone had no effect, pretreatment with progesterone followed by a aPAR1 doubled the number of cells that contained stress fibers. Finally, we evaluated whether the increase in focal contacts and stress fiber formation correlated with cellular migration. As shown in Fig. 6A, treatment with progesterone alone was sufficient to increase migration of

A
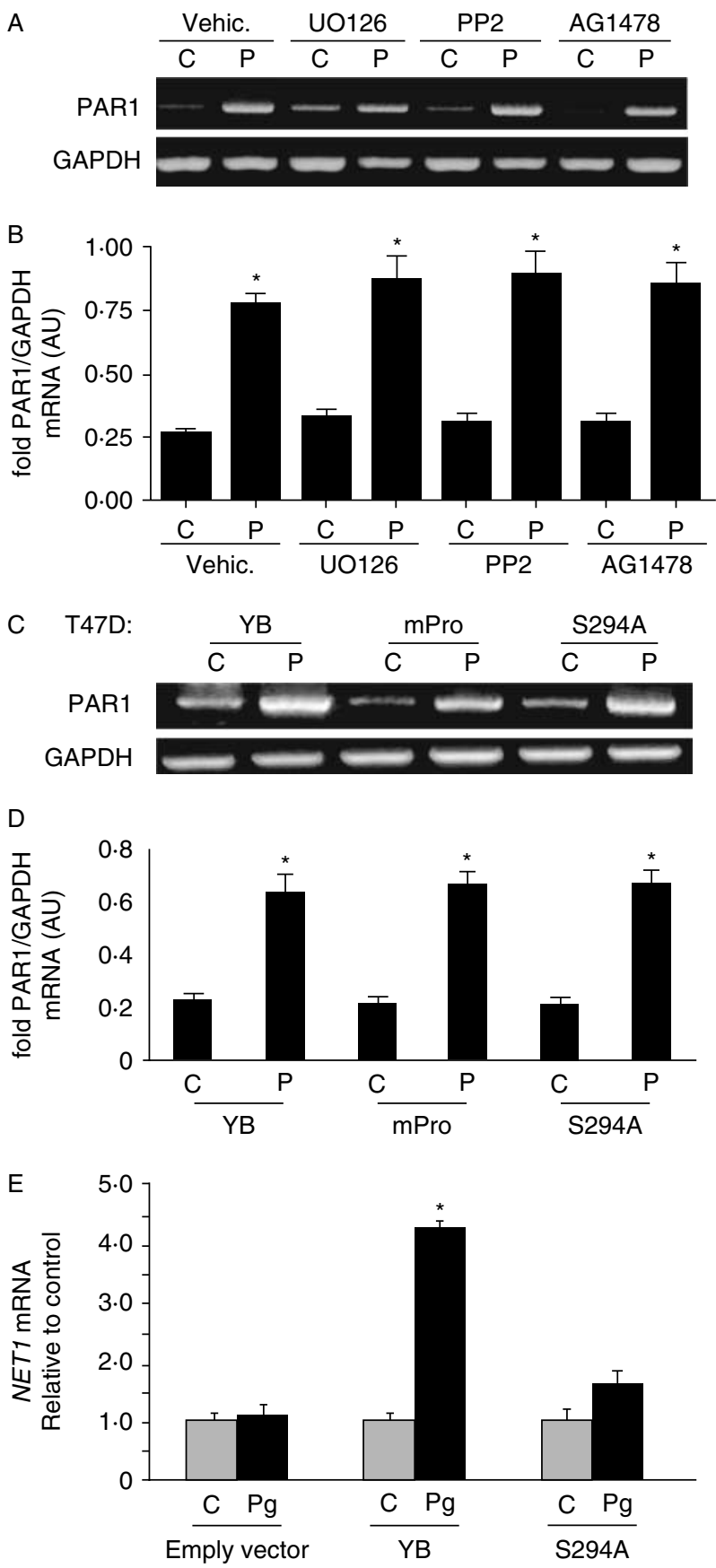

Journal of Endocrinology (2012) 214, 165-175
ZR75 cells. However, pretreatment with progesterone followed by exposure to aPAR 1 significantly enhanced the migratory capacity of ZR-75 cells. Repeating this experiment in the T47D cell line showed that combined progesterone and aPAR 1 treatment also statistically increased breast cancer cell migration. Despite showing tendencies to increase, progesterone or aPAR 1 alone did not demonstrate statistical differences from control. Combining the data suggest that progesterone not only enhances the expression of PAR 1 in breast cancer cells but also sensitizes the cells to PAR1-dependent signaling.

\section{Clinical data mining (Oncomine): PAR1 is overexpressed in} $P R+$ tumors

In the breast cancer cell lines, ZR-75 and T47D, we have demonstrated that progesterone regulates PAR $1 \mathrm{mRNA}$ and protein levels. To investigate whether this in vitro observation was also observed in the clinical setting, we performed data mining in public breast cancer datasets using the Oncomine platform (Rhodes et al. 2004, 2007) We used the TCGA breast cancer mRNA expression dataset within the Oncomine database for our analysis, investigated PAR1 (F2R) mRNA expression in breast tumors, and sorted based on their PR status. The same analysis is represented in two different panels (either a bar chart or box- and -whiskers plot) in Fig. 7. The data show that PAR $1 \mathrm{mRNA}$ is overexpressed in $\mathrm{PR}+$ ve breast tumor samples $(n=191)$ compared with $\mathrm{PR}-$ ve tumors $(n=128)$. PAR 1 is $1 \cdot 281$-fold higher in $\mathrm{PR}+$ ve tumors, with a $P$ value $=0.000259$ and $t$-test $=3 \cdot 516$. Thus, Fig. 7 demonstrates that within the highly robust TCGA dataset, PAR $1 \mathrm{mRNA}$ expression levels are statistically associated with $\mathrm{PR}$-positive breast cancers.

\section{Discussion}

Herein, we demonstrate that progesterone regulates PAR1 at the mRNA and protein levels. This regulation is dependent on the presence of the PR, yet is independent of the c-Src interaction domain (mPRO) and the serine 294

Figure 3 Progesterone does not require the MEK1, Src, or EGFR signaling pathways to upregulate PAR1 mRNA. (A) Representative RT-PCR analysis of ZR-75 cells treated with $10 \mathrm{nM}$ progesterone for 6 h. The MEK1 (U0126), Src (PP2), and EGFR (AG1478) pathway inhibitors were added $30 \mathrm{~min}$ before progesterone addition.

(B) Densitometric analysis from a minimum of three independent experiments shown in panel A. (C) Representative RT-PCR analysis of T47D-YB, T47DmPRO, and T47D-S294A cells treated with $10 \mathrm{nM}$ progesterone for $6 \mathrm{~h}$. (D) Densitometric analysis from a minimum of three independent experiments shown in panel E. T47D cells stably expressing empty vector, wild-type PRB, or the PR mutant S294A were treated in the presence of progestin (R5020, $10 \mathrm{nM}$ ) for $6 \mathrm{~h}$ before the evaluation of NET1 mRNA levels. Progestin is capable of regulating NET1 mRNA via wild-type PR but not in cells expressing PR S294A. In panels B, D, and E, Mann-Whitney analysis was used to determine statistical significance, ${ }^{*} P<0 \cdot 05$. 
A

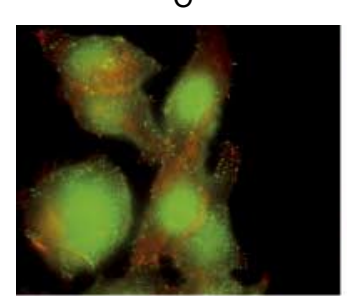

$\mathrm{P}+\mathrm{A} 1$

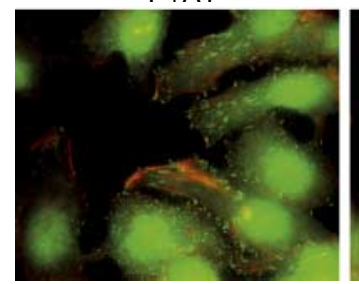

B

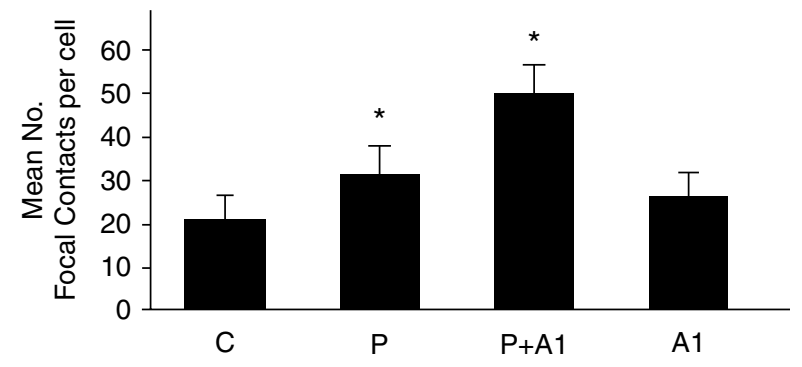

Figure 4 Progesterone pretreatment and PAR1-activating peptide increase the number of focal contacts. (A) ZR-75 cells treated with $10 \mathrm{nM}$ progesterone for $24 \mathrm{~h}$ and/or the peptide that activates PAR1 for 15 min were stained with rhodamine-labeled phalloidin (red), DAPI (blue), and pFAK (green) to visualize F-actin, DNA, and focal contacts respectively. Representative images of merged colors or optical zoom of the focal contacts (black and white internal pictures of the indicated regions) are shown for each condition. (B) Analysis of focal contacts per cell is shown. Averages + S.E.M. of three independent experiments are shown. ${ }^{*} P<0 \cdot 05$. Full colour version of this figure available via http://dx.doi.org/10.1530/JOE-11-0310.

phosphorylation domain. The mechanism of regulation is transcriptional, as demonstrated by the loss of regulation in the presence of the transcriptional inhibitor actinomycin-D, and is most probably through DNA binding as we demonstrated the requirement of an intact PR DNA binding domain and observed a lack of inhibition in the presence of Src and MEK pathway inhibitors. Interestingly, our results demonstrate that phosphorylation of PR at Ser294 does not enhance or alter the ability of progesterone to regulate PAR1. Notably, PR Ser294 phosphorylation prevents Lys388 sumoylation (a repressive modification). Mutant S294A PR is thus heavily sumoylated (at Lys388) relative to the wild-type (i.e. reversibly phosphorylated) receptor (Daniel et al. 2007, Daniel \& Lange 2009). While this regulatory mechanism mediates phosphorylation-dependent PR promoter selection (and depression of transcription), not all endogenous genes are sensitive to these modifications of PR (Daniel \& Lange 2009). As an internal control, we examined the regulation of
NET1, a progestin-responsive gene (Bray et al. 2005) that has been shown previously to be a sumo-sensitive PR target gene (Knutson et al. 2012). Herein, we show that cells stably expressing S294A PR fail to upregulate NET1 relative to cells expressing wild-type PR. Notably, PR-dependent regulation of NET1 and PAR1 occurs at the same time point, demonstrating the selective nature of phospho-Ser294 PR on PR target gene regulation.

Although this is not the first observation that progesterone can regulate $P A R 1$, this is, to our knowledge, the first to demonstrate regulation in breast cancer or mammary glandderived cells. It has not escaped our notice that the timing and mechanism of $P A R 1$ regulation by progesterone is remarkably similar to the progesterone regulation of TF in both T47D and ZR-75 cells (Kato et al. 2005b, Quezada et al. 2010, Henriquez et al. 2011). Advanced breast cancer is associated
A

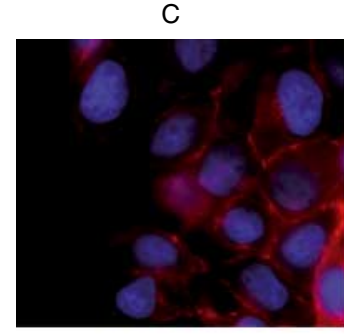

$\mathrm{P}+\mathrm{A} 1$
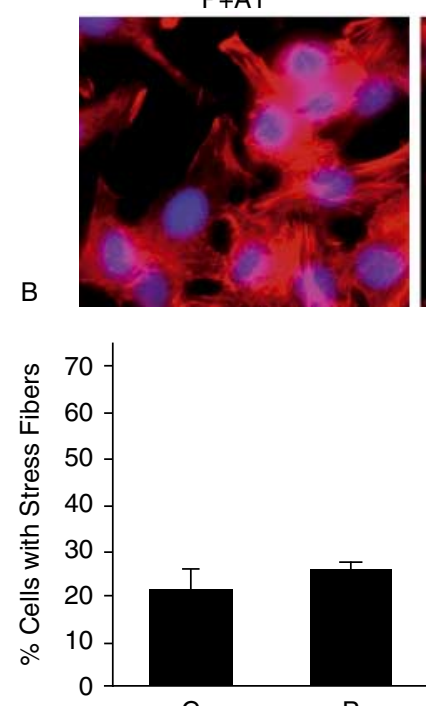

C

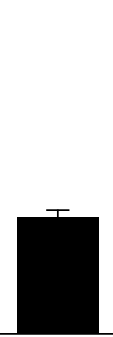

$\mathrm{P}$

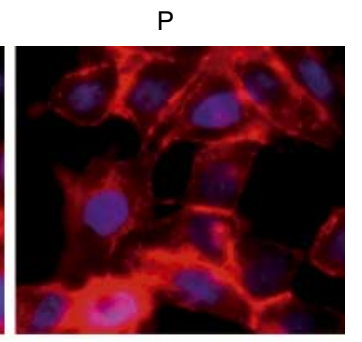

A1

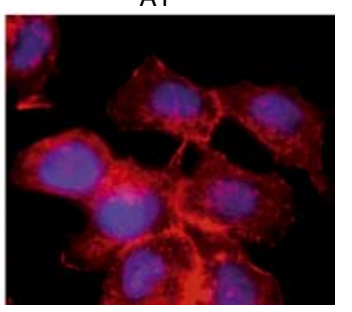

*

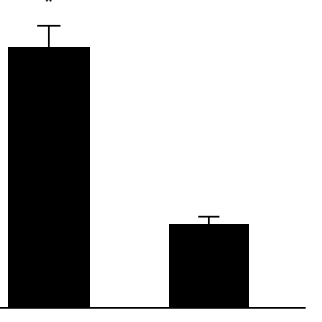

$\mathrm{P}+\mathrm{A} 1$

A1
Figure 5 Progesterone pretreatment and PAR1-activating peptide treatment increase the number of cells with stress fibers. (A) ZR-75 cells treated with $10 \mathrm{nM}$ progesterone for $24 \mathrm{~h}$ and/or the peptide that activates PAR1 for 15 min were stained with rhodaminelabeled phalloidin (red) to visualize polymerized actin. Images are representative of results obtained in at least three independent experiments. (B) The graph shows the quantification of the number of cells that contain stress fibers (examples shown in white arrows) in each condition (shown as a percentage). Values were averaged from three independent experiments. ${ }^{*} P<0 \cdot 05$ compared with control condition. Full colour version of this figure available via http://dx.doi.org/10.1530/JOE-11-0310. 

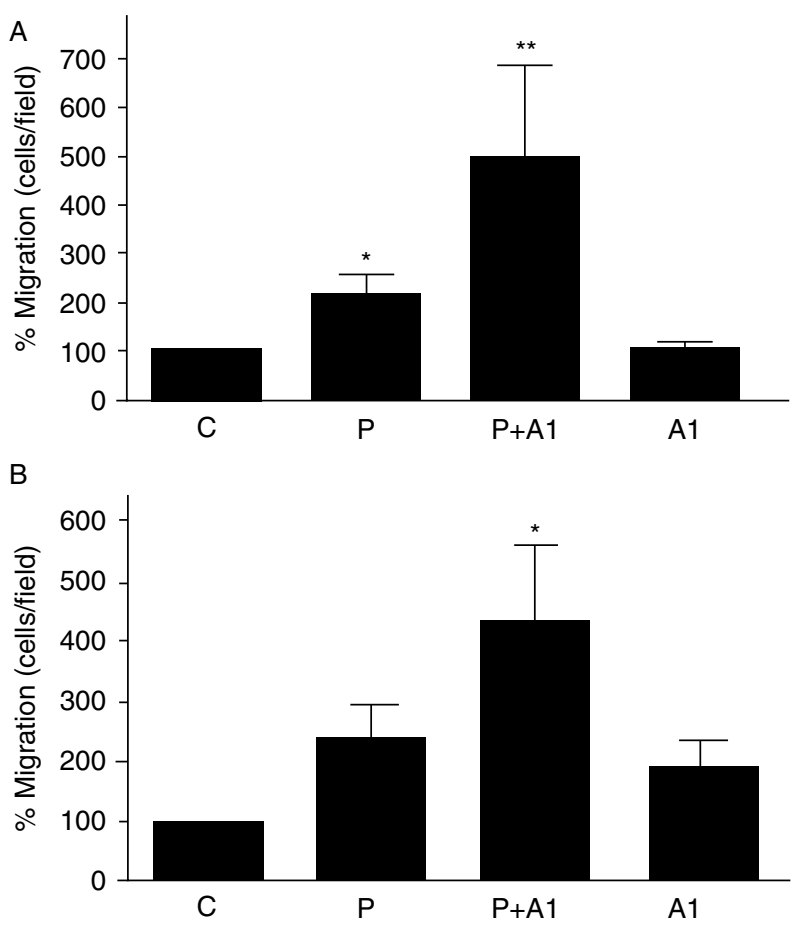

Figure 6 Progesterone pretreatment and PAR1-activating peptide treatment increase breast cancer cell migration. ZR-75 and T47D breast cancer cells were seeded over porous inserts and treated with progesterone $(10 \mathrm{nM})$ or vehicle (control) for $12 \mathrm{~h}$ before the addition of PAR1-activating peptide (aPAR1) or vehicle for a further $12 \mathrm{~h}$. Cells that had migrated through the pores were counted after immunostaining for a marker of epithelial cells, cytokeratin. The data show the mean cell migration ( \pm S.E.M.) of four separate experiments. Statistical analysis was performed by the Mann-Whitney method $\left({ }^{*} P<0.05\right.$ compared with control; $* * P<0 \cdot 05$ compared with progesterone alone).

with a hypercoagulable state that may be triggered or enhanced by the presence of TF and PAR 1 on the surface of cancer cells (Ruf \& Mueller 2006). TF, when bound to factor VIIa, activates the coagulation cascade resulting in FX and thrombin activation and PAR cleavage (Duarte et al. 2006, Albrektsen et al. 2007, Uusitalo-Jarvinen et al. 2007). Given the well-reported links of the coagulation cascade proteins TF and PAR1 with cancer cell angiogenesis, coagulation, migration, and invasion, their enhancement by progesterone may prime breast cancer cells for these functions, thus contributing to the increase in breast cancer incidence seen in postmenopausal women taking HRT. In a cohort of 319 patients from the TCGA dataset, data mining using the Oncomine platform showed that PAR1 mRNA is overexpressed in $\mathrm{PR}+$ compared with $\mathrm{PR}-$ breast tumor samples. The statistically significant $1 \cdot 281$-fold increase in expression in the presence of PR supports our in vitro cell line data and may suggest that in $\mathrm{PR}+$ breast cancer patients taking HRT, the presence of progestins may increase the levels of PAR 1 and deliver a more aggressive phenotype to the cancer cell. The link between $P A R 1$, cancer cell invasion, and poor prognosis is already well established (Even-Ram et al. 1998, Tellez \& Bar-Eli 2003, Yin et al. 2003).

We also demonstrate that progesterone increases the formation of FA complexes as determined by an increase in pFAK in these structures. However, unlike the previous report at $15 \mathrm{~min}$ by Fu et al., we concentrated on longer time points where we had previously shown that progesterone increased invasion of these cells. At $24 \mathrm{~h}$ after progesterone addition, we observed pFAK phosphorylation and a significant increase in FAs. However, progesterone pretreatment of breast cancer cells for $12 \mathrm{~h}$ to increase PAR 1 protein levels followed by a further $12 \mathrm{~h}$ with aPAR 1 significantly increased the number of FAs still further. It is noteworthy that in ZR-75 cells, aPAR1 had no effect after $12 \mathrm{~h}$ on the formation of FAs, despite being able to phosphorylate Erk-1/2. This demonstrates that PAR 1 cannot directly phosphorylate FAK at this time point but requires either PR presence or a process enhanced by the PR, fueling previous speculations in the literature that the assembly at the intercellular domain of PAR1 can selectively mediate cellular processes.

Breast cancer cells are not the first steroid hormoneresponsive cells to show a relation between PAR 1 and pFAK. By immunohistochemistry, Grisaru-Granovsky et al. (2005) observed pFAK in invasive ovarian carcinoma but not in the corresponding normal epithelium. The authors speculated that PAR 1 levels in ovarian carcinoma may transmit signals leading to the phosphorylation of FAK, causing alterations in the integrin functional state and thus promoting ovarian cancer malignancy (Grisaru-Granovsky et al. 2005).

In recent publications by $\mathrm{Fu}$ et al. (2008), it was demonstrated in breast cancer cells that PR signals to moesin, leading to rapid actin remodeling related to cell movement and invasion. The authors speculated that the liganded PR-A, but not $\mathrm{PR}-\mathrm{B}$, interacts with $\mathrm{G}$ coupled proteins, in particular $\mathrm{G} \alpha_{13}$, allowing recruitment of the RhoA/ROCK-2 cascade and subsequent moesin phosphorylation, cell migration, and invasion. Notably, the expression of activated $\mathrm{G} \alpha_{13}$ in cancer cells has been shown to increase invasion (Kelly et al. 2006). Interestingly, in the presence of pertussis toxin, PAR 1 has been shown to induce cellular invasion through a $\mathrm{G} \alpha_{12} / \mathrm{G} \alpha_{13}$ and RhoA/Rho kinase (ROCK)-dependent signaling (Nguyen et al. 2002). PAR1 has recently been shown to signal through a $\mathrm{G} \alpha_{13}$-disheveled pathway to stabilize $\beta$-catenin. Furthermore, a dominant negative $G \alpha_{13}$ or a siRNA against disheveled inhibited or greatly reduced PAR1-induced matrigel invasion (Turm et al. 2010). Whether the increase in PAR 1 by progesterone recruits the $G \alpha_{13^{-}}$ disheveled pathway leading to increased migration is certainly a promising theory that needs to be investigated.

While invasion was shown to be further enhanced by a PAR1-activating ligand in cancer cell lines, the treatment of melanoma cells with the PAR activator thrombin dramatically increased the number of lung metastases in rats (Maragoudakis et al. 2000, Even-Ram et al. 2001). However, in our migration model, we did not observe notable effects with 

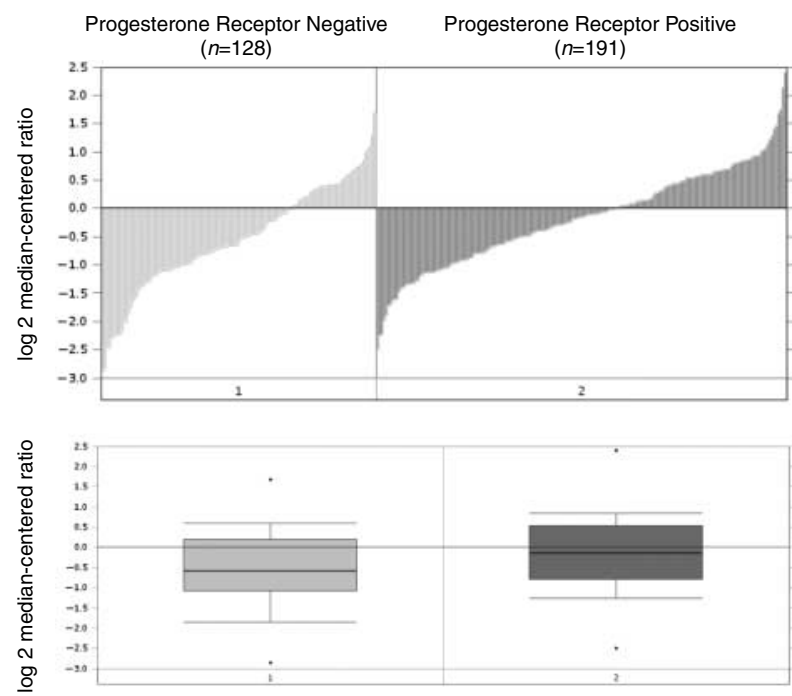

Figure $7 P A R 1$ is overexpressed in PR + tumors: results from the data mining platform, Oncomine. Specifically using the TCGA breast cancer dataset, PAR1 (F2R) mRNA expression in breast tumors sorted by PR status. The same dataset is represented by bar chart in the upper panel and by a box-and-whiskers plot in the lower panel. PAR1 mRNA expression is overexpressed in the PR+ breast tumor samples $(n=191)$ compared with the PR - tumors $(n=128) 1 \cdot 281$-fold higher in PR + tumors $(P$ value $=0 \cdot 000259$, $t$-test $=3 \cdot 516)$. In the upper panel, each bar represents one individual breast tumor sample; with more bars above the 0.0 mRNA expression line in the PR + tumor subgroup. The $Y$-axis is normalized mRNA gene expression values (normalized to the median value of the dataset, and expression levels have been $\log _{2}$ transformed, where positive numbers indicate overexpression and negative numbers indicate underexpression). In the lower panel (box-and-whiskers plot), the dots represent the high/low values, the error bars represent the $90 \% / 10 \%$ values, the top and bottom of the box represent the $75 \% / 25 \%$ values, and the bar in the middle of the box is the median.

aPAR 1 alone. No effect was observed in ZR-75 cells but only tended to increase (not statistically significant) in the T47D cell line. This may reflect the basal levels of PAR 1 in the breast cancer cell lines analyzed herein and/or the tight control that progesterone possesses in progesterone-responsive tissue, allowing activation of certain signaling cascades only in concert with other progesterone-primed pathways.

In an ER- and PR-negative MDA-MB-231-derived cell line, where progesterone markedly inhibits cell growth, progesterone treatment increases the size and number of stress fibers, FA proteins, and focal contacts (Lin et al. 2000). Interestingly, it has also been reported that it is the loss of stress fibers in actin remodeling that is associated with cancer metastasis (Carragher \& Frame 2004, Fu et al. 2008). Although these questions cannot be addressed in this paper, it is important to note that we are examining only one facet of progesterone regulation in the breast cancer cells and in the global picture of replication, proliferation, migration, and metastasis, the notable appearance of stress fibers and FAs on addition of progesterone and PAR1-activating ligand may represent the initial traction that the cells require to stimulate their migratory capacity.

In conclusion, progesterone promotes FAK phosphorylation and breast cancer cell migration. Progesterone transiently regulates PAR $1 \mathrm{mRNA}$ and protein and this increase permits an enhancement in stress fiber and FA formation, providing the necessary adhesion to stimulate migration upon PAR1 activation. Because migration is stimulated under these conditions, a possibility exists that increased FAK phosphorylation is related to an elevated FA turnover, which would account for faster cell migration. Our results, which fit well with clinical data showing an association between increased PAR1 levels and PR + tumors, bring to light new signaling complexities and deliver further understanding of progesterone-mediated breast cancer cell migration. PARs can be effectively targeted by pharmacological agents, such as small-molecule inhibitors, peptides, and antibodies (Leger et al. 2006), and thus, this study may promote the use of anti-PAR 1 and progesterone strategies for the treatment of PR-positive breast cancer.

\section{Declaration of interest}

The authors declare that there is no conflict of interest that could be perceived as prejudicing the impartiality of the research reported.

\section{Funding}

This work was supported by FONDECYT grants 1060495, 1100870 (G I O), and 1080163 (M A C); grant D06I1017 FONDEF (G I O), and The Wellcome Trust International Collaboration grant GR071469 (J J B and G I O). L L is supported by FONDECYT 1110149; FONDECYT-Fondos en Areas Prioritarias 15010006; award number R03TW007810 from the Fogarty International Center-NIH; Iniciativa Científica Milenio (ICM) grant P09-015-F.

\section{References}

Abreu MT, Hughes WE, Mele K, Lyons RJ, Rickwood D, Browne BC, Bennett HL, Vallotton P, Brummer T \& Daly RJ 2011 Gab2 regulates cytoskeletal organization and migration of mammary epithelial cells by modulating RhoA activation. Molecular Biology of the Cell 22 105-116. (doi:10.1091/mbc.E10-03-0185)

Albrektsen T, Sorensen BB, Hjorto GM, Fleckner J, Rao LV \& Petersen LC 2007 Transcriptional program induced by factor VIIa-tissue factor, PAR 1 and PAR2 in MDA-MB-231 cells. Journal of Thrombosis and Haemostasis $\mathbf{5}$ 1588-1597. (doi:10.1111/j.1538-7836.2007.02603.x)

Avalos AM, Arthur WT, Schneider P, Quest AF, Burridge K \& Leyton L 2004 Aggregation of integrins and RhoA activation are required for Thy-1induced morphological changes in astrocytes. Journal of Biological Chemistry 279 39139-39145. (doi:10.1074/jbc.M403439200)

Beral V 2003 Breast cancer and hormone-replacement therapy in the Million Women Study. Lancet 362 419-427. (doi:10.1016/S0140-6736(03)14596-5) Boonyaratanakornkit V, Scott MP, Ribon V, Sherman L, Anderson SM, Maller JL, Miller WT \& Edwards DP 2001 Progesterone receptor contains a proline-rich motif that directly interacts with $\mathrm{SH} 3$ domains and activates c-Src family tyrosine kinases. Molecular Cell 8 269-280. (doi:10.1016/ S1097-2765(01)00304-5) 
Bray JD, Jelinsky S, Ghatge R, Bray JA, Tunkey C, Saraf K, Jacobsen BM, Richer JK, Brown EL, Winneker RC et al. 2005 Quantitative analysis of gene regulation by seven clinically relevant progestins suggests a highly similar mechanism of action through progesterone receptors in T47D breast cancer cells. Journal of Steroid Biochemistry and Molecular Biology 97 328-341. (doi:10.1016/j.jsbmb.2005.06.032)

Burridge K \& Chrzanowska-Wodnicka M 1996 Focal adhesions, contractility, and signaling. Annual Review of Cell and Developmental Biology 12 463-518. (doi:10.1146/annurev.cellbio.12.1.463)

Carragher NO \& Frame MC 2004 Focal adhesion and actin dynamics: a place where kinases and proteases meet to promote invasion. Trends in Cell Biology 14 241-249. (doi:10.1016/j.tcb.2004.03.011)

Carvajal A, Espinoza N, Kato S, Pinto M, Sadarangani A, Monso C, Aranda E, Villalon M, Richer JK, Horwitz KB et al. 2005 Progesterone pre-treatment potentiates EGF pathway signaling in the breast cancer cell line ZR-75. Breast Cancer Research and Treatment 94 171-183. (doi:10.1007/s10549-0057726-6)

Critchley DR 2000 Focal adhesions - the cytoskeletal connection. Current Opinion in Cell Biology 12 133-139. (doi:10.1016/S0955-0674 (99)00067-8)

Critchley HO, Kelly RW, Baird DT \& Brenner RM 2006 Regulation of human endometrial function: mechanisms relevant to uterine bleeding. Reproductive Biology and Endocrinology 4 (Suppl 1) S5. (doi:10.1186/14777827-4-S1-S5)

Daniel AR \& Lange CA 2009 Protein kinases mediate ligand-independent derepression of sumoylated progesterone receptors in breast cancer cells. PNAS 106 14287-14292. (doi:10.1073/pnas.0905118106)

Daniel AR, Faivre EJ \& Lange CA 2007 Phosphorylation-dependent antagonism of sumoylation derepresses progesterone receptor action in breast cancer cells. Molecular Endocrinology 21 2890-2906. (doi:10.1210/me. 2007-0248)

Duarte M, Kolev V, Soldi R, Kirov A, Graziani I, Oliveira SM, Kacer D, Friesel R, Maciag T \& Prudovsky I 2006 Thrombin induces rapid PAR1-mediated non-classical FGF1 release. Biochemical and Biophysical Research Communications 350 604-609. (doi:10.1016/j.bbrc. 2006.09.107)

Engel LW, Young NA, Tralka TS, Lippman ME, O’Brien SJ \& Joyce MJ 1978 Establishment and characterization of three new continuous cell lines derived from human breast carcinomas. Cancer Research 38 3352-3364.

Even-Ram S, Uziely B, Cohen P, Grisaru-Granovsky S, Maoz M, Ginzburg Y, Reich R, Vlodavsky I \& Bar-Shavit R 1998 Thrombin receptor overexpression in malignant and physiological invasion processes. Nature Medicine 4 909-914. (doi:10.1038/nm0898-909)

Even-Ram SC, Maoz M, Pokroy E, Reich R, Katz BZ, Gutwein P, Altevogt P \& Bar-Shavit R 2001 Tumor cell invasion is promoted by activation of protease activated receptor- 1 in cooperation with the alpha vbeta 5 integrin. Journal of Biological Chemistry 276 10952-10962. (doi:10.1074/jbc.M007027200)

Faivre EJ \& Lange CA 2007 Progesterone receptors upregulate Wnt-1 to induce epidermal growth factor receptor transactivation and c-Srcdependent sustained activation of Erk1/2 mitogen-activated protein kinase in breast cancer cells. Molecular and Cellular Biology 27 466-480. (doi:10.1128/MCB.01539-06)

Faivre E, Skildum A, Pierson-Mullany L \& Lange CA 2005 Integration of progesterone receptor mediated rapid signaling and nuclear actions in breast cancer cell models: Role of mitogen-activated protein kinases and cell cycle regulators. Steroids 70 418-426. (doi:10.1016/j.steroids.2005.02.012)

Faivre EJ, Daniel AR, Hillard CJ \& Lange CA 2008 Progesterone receptor rapid signaling mediates serine 345 phosphorylation and tethering to specificity protein 1 transcription factors. Molecular Endocrinology 22 823-837. (doi:10.1210/me.2007-0437)

Fu XD, Giretti MS, Baldacci C, Garibaldi S, Flamini M, Sanchez AM, Gadducci A, Genazzani AR \& Simoncini T 2008 Extra-nuclear signaling of progesterone receptor to breast cancer cell movement and invasion through the actin cytoskeleton. PLoS ONE 3 e2790. (doi:10.1371/journal.pone. 0002790)
Grisaru-Granovsky S, Salah Z, Maoz M, Pruss D, Beller U \& Bar-Shavit R 2005 Differential expression of protease activated receptor 1 (Par1) and pY397FAK in benign and malignant human ovarian tissue samples. International Journal of Cancer 113 372-378. (doi:10.1002/ijc.20607)

Guan JL 2010 Integrin signaling through FAK in the regulation of mammary stem cells and breast cancer. IUBMB Life 62 268-276. (doi:10.1002/iub.311)

Hague S, Oehler MK, MacKenzie IZ, Bicknell R \& Rees MC 2002 Protease activated receptor-1 is down regulated by levonorgestrel in endometrial stromal cells. Angiogenesis 5 93-98. (doi:10.1023/A:1021510723157)

Henriquez S, Calderon C, Quezada M, Oliva B, Bravo ML, Aranda E, Kato S, Cuello MA, Gutierrez J, Quest AF et al. 2011 Progesterone utilizes distinct membrane pools of tissue factor to increase coagulation and invasion and these effects are inhibited by TFPI. Journal of Cellular Physiology 226 3278-3285. (doi:10.1002/jcp.22689)

Herkert O, Kuhl H, Sandow J, Busse R \& Schini-Kerth VB 2001 Sex steroids used in hormonal treatment increase vascular procoagulant activity by inducing thrombin receptor (PAR-1) expression: role of the glucocorticoid receptor. Circulation 104 2826-2831. (doi:10.1161/hc4801.099737)

Hirano K 2007 The roles of proteinase-activated receptors in the vascular physiology and pathophysiology. Arteriosclerosis, Thrombosis, and Vascular Biology 27 27-36. (doi:10.1161/01.ATV.0000251995.73307.2d)

Horwitz KB, Mockus MB \& Lessey BA 1982 Variant T47D human breast cancer cells with high progesterone-receptor levels despite estrogen and antiestrogen resistance. Cell 28 633-642. (doi:10.1016/0092-8674 (82)90218-5)

Horwitz KB, Sheridan PL, Wei LL \& Krett NL 1990 Human progesterone receptors: synthesis, structure, and phosphorylation. Progress in Clinical and Biological Research 322 41-52.

Kato S, Pinto M, Carvajal A, Espinoza N, Monso C, Bravo L, Villalon M, Cuello M, Quest AF, Suenaga A et al. 2005a Tissue factor is regulated by epidermal growth factor in normal and malignant human endometrial epithelial cells. Thrombosis and Haemostasis 94 444-453.

Kato S, Pinto M, Carvajal A, Espinoza N, Monso C, Sadarangani A, Villalon M, Brosens JJ, White JO, Richer JK et al. 2005b Progesterone increases tissue factor gene expression, procoagulant activity, and invasion in the breast cancer cell line ZR-75-1. Journal of Clinical Endocrinology and Metabolism 90 1181-1188. (doi:10.1210/jc.2004-0857)

Kelly P, Stemmle LN, Madden JF, Fields TA, Daaka Y \& Casey PJ 2006 A role for the G12 family of heterotrimeric $G$ proteins in prostate cancer invasion. Journal of Biological Chemistry 281 26483-26490. (doi:10.1074/jbc. M604376200)

Knutson TP, Daniel AR, Fan D, Silverstein KAT, Covington KR, Fuqua SAW \& Lange CA 2012 Phosphorylated and SUMO-deficient progesterone receptors drive proliferative gene signatures during breast cancer progression. Breast Cancer Research 14 R95.

Landis RC 2007 Protease activated receptors: clinical relevance to hemostasis and inflammation. Hematology/Oncology Clinics of North America 21 103-113. (doi:10.1016/j.hoc.2006.11.005)

Lange CA 2008 Integration of progesterone receptor action with rapid signaling events in breast cancer models. Journal of Steroid Biochemistry and Molecular Biology 108 203-212. (doi:10.1016/j.jsbmb.2007.09.019)

Lange CA, Shen T \& Horwitz KB 2000 Phosphorylation of human progesterone receptors at serine-294 by mitogen-activated protein kinase signals their degradation by the 26S proteasome. PNAS 97 1032-1037. (doi:10.1073/pnas.97.3.1032)

Leger AJ, Covic L \& Kuliopulos A 2006 Protease-activated receptors in cardiovascular diseases. Circulation 114 1070-1077. (doi:10.1161/CIRCULATIONAHA.105.574830)

Leung T, Chen XQ, Manser E \& Lim L 1996 The p160 RhoA-binding kinase ROK alpha is a member of a kinase family and is involved in the reorganization of the cytoskeleton. Molecular and Cellular Biology $\mathbf{1 6}$ 5313-5327.

Lin VC, Ng EH, Aw SE, Tan MG \& Bay BH 2000 Progesterone induces focal adhesion in breast cancer cells MDA-MB-231 transfected with progesterone receptor complementary DNA. Molecular Endocrinology 14 348-358. (doi:10.1210/me.14.3.348) 
Maragoudakis ME, Tsopanoglou NE, Andriopoulou P \& Maragoudakis MM 2000 Effects of thrombin/thrombosis in angiogenesis and tumour progression. Matrix Biology 19 345-351. (doi:10.1016/S0945053X(00)00079-2)

Mitchell SE, Robinson JJ, King ME \& Williams LM 2005 Proteinaseactivated receptors in ovine cervical function. Reproduction, Fertility, and Development 17 693-699. (doi:10.1071/RD05032)

Nguyen QD, Faivre S, Bruyneel E, Rivat C, Seto M, Endo T, Mareel M, Emami S \& Gespach C 2002 RhoA- and RhoD-dependent regulatory switch of Galpha subunit signaling by PAR-1 receptors in cellular invasion. FASEB Journal 16 565-576. (doi:10.1096/fj.01-0525com)

Ossovskaya VS \& Bunnett NW 2004 Protease-activated receptors: contribution to physiology and disease. Physiological Reviews 84 579-621. (doi:10.1152/physrev.00028.2003)

Pellegrin S \& Mellor H 2007 Actin stress fibres. Journal of Cell Science 120 3491-3499. (doi:10.1242/jcs.018473)

Pierson-Mullany LK \& Lange CA 2004 Phosphorylation of progesterone receptor serine 400 mediates ligand-independent transcriptional activity in response to activation of cyclin-dependent protein kinase 2. Molecular and Cellular Biology 24 10542-10557. (doi:10.1128/MCB.24.24.10542-10557. 2004)

Quezada MDJ, Henriquez S, Bravo ML, Aranda E, Oliva B, Villalon M, Kato S, Cuello MA, Brosens JJ, Lange CA et al. 2010 2-Methoxyestradiol inhibits progesterone mediated tissue factor expression and activity in breast cancer cells. Hormones \& Cancer 1 117-126. (doi:10.1007/s12672-010-0019-5)

Rhodes DR, Yu J, Shanker K, Deshpande N, Varambally R, Ghosh D, Barrette T, Pandey A \& Chinnaiyan AM 2004 ONCOMINE: a cancer microarray database and integrated data-mining platform. Neoplasia 6 1-6.

Rhodes DR, Kalyana-Sundaram S, Mahavisno V, Varambally R, Yu J, Briggs BB, Barrette TR, Anstet MJ, Kincead-Beal C, Kulkarni P et al. 2007 Oncomine 3.0: genes, pathways, and networks in a collection of 18,000 cancer gene expression profiles. Neoplasia 9 166-180. (doi:10.1593/neo.07112)

Rickles FR 2006 Mechanisms of cancer-induced thrombosis in cancer. Pathophysiology of Haemostasis and Thrombosis 35 103-110. (doi:10.1159/ 000093551)

Ruf W \& Mueller BM 2006 Thrombin generation and the pathogenesis of cancer. Seminars in Thrombosis and Hemostasis 32 (Suppl 1) 61-68. (doi:10.1055/s-2006-939555)
Sartorius CA, Groshong SD, Miller LA, Powell RL, Tung L, Takimoto GS \& Horwitz KB 1994 New T47D breast cancer cell lines for the independent study of progesterone B- and A-receptors: only antiprogestin-occupied B-receptors are switched to transcriptional agonists by cAMP. Cancer Research 54 3868-3877.

Schaller MD 2008 Calcium-dependent Pyk2 activation: a role for calmodulin? Biochemical Journal 410 e3-e4. (doi:10.1042/BJ20080133)

Schaller MD, Borgman CA, Cobb BS, Vines RR, Reynolds AB \& Parsons JT 1992 pp125FAK a structurally distinctive protein-tyrosine kinase associated with focal adhesions. PNAS 89 5192-5196. (doi:10.1073/pnas.89.11.5192)

Tellez C \& Bar-Eli M 2003 Role and regulation of the thrombin receptor (PAR-1) in human melanoma. Oncogene 22 3130-3137. (doi:10.1038/sj. onc.1206453)

Turm H, Maoz M, Katz V, Yin YJ, Offermanns S \& Bar-Shavit R 2010 Protease-activated receptor-1 (PAR1) acts via a novel Galpha13-dishevelled axis to stabilize beta-catenin levels. Journal of Biological Chemistry $28515137-$ 15148. (doi:10.1074/jbc.M109.072843)

Uusitalo-Jarvinen H, Kurokawa T, Mueller BM, Andrade-Gordon P, Friedlander M \& Ruf W 2007 Role of protease activated receptor 1 and 2 signaling in hypoxia-induced angiogenesis. Arteriosclerosis, Thrombosis, and Vascular Biology 27 1456-1462. (doi:10.1161/ATVBAHA.107.142539)

Yin YJ, Salah Z, Grisaru-Granovsky S, Cohen I, Even-Ram SC, Maoz M, Uziely B, Peretz T \& Bar-Shavit R 2003 Human protease-activated receptor 1 expression in malignant epithelia: a role in invasiveness. Arteriosclerosis, Thrombosis, and Vascular Biology 23 940-944. (doi:10.1161/ 01.ATV.0000066878.27340.22)

Yuan TC \& Lin MF 2004 Protease-activated receptor 1: a role in prostate cancer metastasis. Clinical Prostate Cancer 3 189-191.

Zhao J \& Guan JL 2009 Signal transduction by focal adhesion kinase in cancer. Cancer Metastasis Reviews 28 35-49. (doi:10.1007/s10555-008-9165-4)

Received in final form 7 May 2012

Accepted 15 May 2012

Made available online as an Accepted Preprint 16 May 2012 